\title{
Preschool Teachers' Short-term Training Strategy based on Teacher Needs
}

\author{
Zheng Xiaoying \\ (Qiongtai Teachers College, Hainan, Haikou, 571127)
}

Keywords: Preschool teachers;Short-term focus training;Teachers' needs;Strategy

\begin{abstract}
In order to adapt to the rapid development of preschool education, preschool teacher' $\mathrm{s}$ short-term training was born to encourage teachers to be able to quickly adapt to the development of preschool education,timely update ideas, learn new teaching methods and skills, and encourage teachers to improve their capacity. The purpose of this paper is to analyzes problems existing in preschool teachers short-term the centralized training, build up early childhood teachers short-term focus training strategy based on teachers' needs, and promote efficient, practical and convenient short-term focus training.

Preschool education is the beginning of lifelong education, which has a cornerstone role in national education. "Education is based on teachers". Without good teachers team, it is difficult to guarantee scientific and reasonable teaching methods, and guarantee children's healthy and happy growth. Several Opinions on the Current Development of Pre-school Education of State Council explicitly puts forward the importance of "strengthening the construction of teachers", requires to strengthen preschool teachers team construction through a variety of ways, and puts forward pre-school education teacher training system. Short-term training has its advantages, as to improve teachers' quality in a short time, and ensure the quality of teaching. However, problems in the process of practical training should not be ignored, and need to be faced actively with deep analysis. Preschool teachers' short-term focus on training strategy under teachers' demand becomes the hot topic of research.
\end{abstract}

\section{Deep understanding of the connotation of preschool teachers' short-term training under teachers need}

Teachers' short-term training focuses mainly on kindergarten, deputy director, conservationists and other related staff, and its main purpose is to improve the overall quality of the contingent of preschool teachers. Training demand mainly comes from enterprise training theory with combination of preschool teachers' quality, attitudes, beliefs, knowledge, skills and behavior through the need for training to shorten the gap between teachers. This needs give full consideration to the actual situation of preschool teachers in the process of teachers' training to establish teacher's study characteristic and diathesis of training mode in order to make teachers promote on the basis of original quality. Teachers demand mainly includes the following aspects: training content, training form, training teachers, training time and place and way of examination and etc. However, in concrete implementation process, there are many problems and difficulties, and need the general education workers to deep analyze and research, so as to explore a set of feasible, meet- needs teachers training strategy to promote the development of preschool teachers' overall quality, and promote the development of pre-school education career.

\section{Explore the reason for problems in preschool teachers short-term focus training under teachers' demand}

A. The contradiction between training content and teachers' demand

Training content is the key and core of training, which often tends to "professional knowledge" 
and "professional philosophy" relevant knowledge with much theory knowledge. For early childhood teachers, it is difficult to put theory into practice in teaching practice, and very well put it into lively teaching activities, thus losing the meaning of theory training. This makes the separation between the content of training and teaching practice. Manual production class, for example, is hard to be conducted because of kindergarten's own budget problems, and teachers can only feel pity not to operate. Therefore, teacher is more eager to get some training on "professional ability", enable teachers to gain some professional ability in actual operation. We can also see that preschool teachers have little attention of theoretical knowledge, and one-sided think it is not helpful in teaching practice. There are some deviations in understanding.

B. The contradiction analysis between training form and teachers' demand

Training is often in the form of a combination of lectures and case analysis. Early childhood teachers listen to lectures or case study, and organize teachers' research, evaluation, reflection so as to obtain some teaching methods and skills. For early childhood teachers, however, they hope to have more opportunity to"watch out", go to a better kindergarten to visit, observe and learn, so that they can expand their horizons, and arouse the enthusiasm of teachers to flexibly participate in training. Preschool teachers also believe that training in the process is the form of practice,and often lack of certain interactive. Lecture, a concentrated and efficient training method,is adopted because of short training time,more content, more people, and it is difficult to make the development of interactive discussion. Lack of interaction is the problem and confusion early childhood teachers often encounter in actual teaching.

C. The contradiction between training teachers and teachers demand

Training teachers' present situation, compared with teachers' demand, cannot meet the needs of preschool teachers. Although training teachers are professional stronger, and mostly from first teaching line, some preschool teachers are facing problemsin teaching practice but cannot related to other teachers to give answers. Some teachers want to participate in relevant professional training,but cannot get this information. For example, remote preschool teachers, hope to have a pediatrician for training, because the kindergarten has no health care doctors, once encounter emergencies, doctor can't first time appear in the child's side, and this will require preschool teachers who have some knowledge in this field, so that they can get regular, scientific guidance and training in order to ensure the health of children. It is visible thatthere is a lack of comprehensive training project,and lack of related teachers, which requires the combination of teachers need to supplement in order to make training more comprehensive and practical.

D. The contradiction between training time and place and teachers' demand

Children's short-term concentrated training time generally takes up teachers' weekend and work time, such as "preschool teacher cultivate"beginning time is Friday, ending time is Thursday. When preschool teachers are concerned, however, most of early childhood teachers have time to do some adjustment, which will report to schedule on Saturday, ending on Friday, so that teachers can time before and after flexibly. Teachers complain that after Thursday is over, they would not only face car fatigue and Friday's work, which makes teachers feel inadequate preparation and mind and body exhaustion. Teachers suggest that training should be arranged in summer and winter vacation, training while children are out so that all aspects of work will not be delayed.

Teachers hope to arrange site with convenienttraffic, easy to find, which will reduce a lot of time and energy, thus more focus on training work.

E. The contradiction between inspection method and teachers' demand

Training assessment is mainly combining way of process examination and structure implementation, and evaluate according to attendance, job submission in form of teaching reflection. For preschool teachers, they pay more attention to "participation in class discussions". Because in the process of discussion, preschool teachers express problems in their mind, conquer together through teachers' wisdom, and from which they learn a lot of teachers' practical knowledge and skills. As well as follow-up examination, early childhood teachers often perform very well in the process of training, the understanding of classroom is in place, but in concrete implementation of work, there is a certain inertia, anduntimely application of learning in teaching. Teachers believe 
that follow-up inspection check ensures the persistence of training, enables teachers' combination of training content and teaching practice in daily life.

\section{Based on teacher, establish preschool teachers short-term focus training strategy under teachers' demand}

A. Establish training content teacher needs and highlight practice

In the process of organizing training, in addition to teach knowledge, as far as possible take good care of the needs of early childhood teachers, establish some theories contact actual practice, and make full training content. Theory teaching should be with certain cases to resonate with most teachers' teaching practice, get the incentive of preschool teachers' interest in learning, and focus on learning related knowledge so as to guide and correct the bad habits in their teaching and problems. Some of early childhood teachers, on the other hand, have weak theoretical foundation, especially some private kindergarten teachers, lack of relevant professional knowledge learning, so it is difficult to understand the content of training teachers and absorb the explanations. Training teachers have to give these teachers more instances, using a comprehensible way to help them understand. Preschool teachers put forward operational and practical training, and training teachers can combine theory and practice, provide more hands-on opportunities for early childhood teachers, form the process into intuitive seen theory, thus deepening the understanding and application of preschool teachers.

B. Take teachers demanded training form with flexible diversification

Pluralism and diversity training methods develop with "the development of preschool teachers" in order to give full play to the initiative and enthusiasm of early childhood teachers, and avoid passive listeners in the process of preschool teachers training. To carry out some activities early childhood teachers can participate in, such as criticism, evaluation, common problems seminars and other training activities, make preschool teachers "leading role", and earnestly implement the ability of preschool teachers. In addition, training should pay attention to the acceptance of preschool teachers, adopt the method of preschool teachers easy to accept, and avoid "cramming" training. Training teachers are very excited while early childhood teachers are dull. Simply don't know how to operate and struggle in action. In the face of this situation, we should take more demonstration course, practice course to make intuitive vivid touch by preschool teachers and combination of theory and practice, and show abstract theoretical knowledge through concrete forms.

According to the need of preschool teachers, we can also provide some elective courses to provide preschool teachers more learning opportunities meet the needs of their hearts, have the freedom to choose according to their own needs, and enhance pertinence, diversity in the form of training.

C. Select training teachers and realize artistic

On the choice of training teachers, we can fully meet the demand of teachers andget more first line teachers in training. Excellent training experts may not be suitable for preschool teachers demand.Some remote kindergartens with relatively backward facilities and materials, and some teaching theory don't look right in their kindergarten. Then we can teach according to their aptitude, hire some similar remote areas excellent preschool teachers of management and education as training teachers so to ensure that the common language between teachers and students, and make the training more effectiveness. To meet the demand of preschool teachers, related problems are interpreted, thus extended fields, such as dietitian or pediatrician can enter into training teachers' category to ensure that the training is more practical, wider, and meet the needs of different early childhood teachers to improve the comprehensive quality of preschool teachers in an all-round way.

D. Adjust time and place according to teacher needs and ensure humanization

Training time can be properly adjusted as far as possible to meet the requirements of preschool teachers. Such as change check-in time to Saturday or Sunday to enable preschool teachers have their own free time before and after the training, and actively adjust their work. Arrange end time on Friday and give preschool teachers more time to rest and time to prepare for class on Monday, 
and make the arrangement more humanization. In addition, in order to satisfy some kindergarten preschool teachers' shortage tense situation, appropriately arrange training time in summer and winter vacations. Preschool teachers may focus more on learning and have enough time to arrange early childhood teachers out to view and listen to teacher evaluation.

On the choice of training site, try to arrange traffic developed places, and reduce the timeearly childhood teachers spend on the road and make more time for training, learning, and arrange their own activities.

E. Improve the appraisal system on teachers demand and enhance the effectiveness

Examination is the main way testing preschool teachers accepted, and general evaluation is according to attendance, job submission, teaching reflection and evaluation. In order to enhance training effect, we can add a few aspects of inspection. First of all, strengthen the practice of early childhood teachers in the process of training to make what they have learned applied to practical teaching to detect early childhood teachers accepting situation about the course; Second, integrate preschool teachers' participation into the discussion, make each preschool teacher combine their teaching ideas, enhance thinking collision between each other, thus help early childhood teachers realize the breakthrough and innovation of themselves; Third, adhere to follow-up tracking guidance, and encourage preschool teachers bravely face concrete implementation problems and difficulties in the process with persistence in order to play a long effect. At the same time, combine with related supervision and examination, thereby enlarge appraisal to preschool teachers work in order to improve training effect.

\section{IV.Conclusion}

Preschool teachers overall quality is not to be improved by one or two short concentrated training. It needsorderly plan in preschool teacher training according to different teaching goals in order to make the training content, way and method suit the needs of preschool teachers' development. Fully combine teachers' training with practice. In line with the Times, make training requirement for preschool teachers and dig out efficiency and practicability of short-term focus training. Although the state attaches great importance to preschool education teachers' quality development, some problems still exist in practical training, which reduces the expected effect of training. As long as firm priority to "teachers", continuously explore short-term training strategy under teachers demand can make training deliver positive energy, and comprehensively promote the improvement of preschool teachers' overall quality.

\section{References}

[1] Nan Wangsheng. Short-term children training needs survey---- take Dingxi Teachers Institute 2012 preschool teacher training project [short-term concentrated training] for example [J]. Journal of Gansu Education. 2013.17

[2] ZuoRuihong, Li Yan. "Cultivation Plan" short-term focus training project implementation issues and Suggestions---- take Heilongjiang province "preschool teachers cultivation plan" short-term concentrated training program for example [J]. Journal of Continuing Education Research. 2013.10

[3] Yu Xin. Teacher training project management process and task research ---- take "countries culture plan" short-term intensive training program for example [C]. Teacher Training Research and Comment. The Second Album.

[4] Dang Tingjun. Problem and improvement for local colleges and universities to participate in rural teachers' "cultivation plan"---- take short-term focus training programs in "cultivation plan" for example [J]. China's Adult Education. 2011 